\title{
Experimental study on condensation and evaporation flow inside horizontal three dimensional enhanced tubes
}

\author{
Wei Li ${ }^{\text {a }}{ }^{*}$, JingXiang Chen ${ }^{\text {a }}$, Hua Zhu ${ }^{\text {a }}$, David J. Kukulka ${ }^{b}$, W.J. Minkowycz ${ }^{\text {, }}$ \\ ${ }^{a}$ Department of Energy Engineering, Zhejiang University, Hangzhou 310027, China \\ ${ }^{b}$ State University of New York College at Buffalo, 1300 Elmwood Avenue Buffalo, New York
} 14222,USA

${ }^{c}$ Department of Mechanical and Industrial Engineering (M/C 251), University of Illinois at Chicago, 842 West Taylor Street, Room 2049 ERF, Chicago, IL 60607-7022

*Corresponding author.Tel./ Fax: +86 571 87952244; E-mail addresses: weili96@zju.edu.cn. 


\begin{abstract}
Experimental investigations of tube side condensation and evaporation in two 3-D enhanced heat transfer (2EHT) tubes were compared to the performance of a smooth surface copper tube. The equivalent outer diameter of all the tubes was $12.7 \mathrm{~mm}$ with an inner diameter of $11.5 \mathrm{~mm}$. Both the inner and outer surfaces of the 2EHT tubes are enhanced by longitudinal grooves with a background pattern made up by an array of dimples/embossments. Experimental runs were performed using R410A as the working fluid, over the quality range of $0.2-0.9$. For evaporation, the heat transfer coefficient ratio (compares the heat transfer coefficient of the enhanced tube to that of a smooth tube) of the 2EHT tubes is $1.11-1.43$ (with an enhanced surface area ratio of 1.03) for mass flux rate that ranges from 80 to $200 \mathrm{~kg} / \mathrm{m}^{2} \mathrm{~s}$. For condensation, the heat transfer coefficient ratio range is $1.1-1.16$ (with an enhanced surface area ratio of 1.03) for mass flux that ranges from 80 to $260 \mathrm{~kg} / \mathrm{m}^{2} \mathrm{~s}$. Frictional pressure drop values for the 2EHT tubes are very similar to each other. Heat transfer enhancement in the 2EHT tubes is mainly due to the dimples and grooves in the inner surface that create an increased surface area and interfacial turbulence; producing higher heat flux from wall to working fluid, flow separation, and secondary flows. A comparison was performed to evaluate the enhancement effect of the 2EHT tubes using a defined performance factor and this indicates that the 2EHT tubes provides a better heat transfer coefficient under evaporation conditions.
\end{abstract}

Keywords: condensation, evaporation, enhanced heat transfer, three dimensional enhanced tube, performance factor 


\section{Introduction}

Two-phase flow heat exchangers are commonly used in a variety of industries (HVAC, refrigeration, process, etc.); it is often desired to improve the heat transfer coefficient in those heat exchangers by utilizing enhanced tubes that can increase the heat transfer coefficient (HTC) and increase performance. Understanding of the heat transfer and pressure drop characteristics of these enhanced heat transfer tubes is required in order to implement them in high performance designs. Although there have been previous works that have examined this problem, more studies are needed since improved surface enhancement methods have been developed that produce new types of tubes.

Previous studies [1-9] have been performed to evaluate the tube side heat transfer and pressure drop characteristics of horizontal micro-fin tubes in two-phase flow field. Webb and Kim [1] summarized their and many previous authors' data results, and proposed many principles and correlations of enhanced heat transfer which can be applied to different situations including tube side condensation and evaporation with different tube geometry. Cavallini et al. [2] presented a detailed review of condensation heat transfer in smooth and enhanced tubes. They discussed the limitations of using previously reported semi-empirical correlations that are commonly used and accepted for some enhanced tubes to predict the performance of all enhanced or non-circular tubes; inaccurate results may be predicted when these correlations are used to predict the heat transfer performance of some brand new applications, such as flattened tubes and the newly designed three dimensional enhanced heat transfer tubes (2EHT) in this study. Rollmann et al. [3] studied the flow boiling of R407C and $\mathrm{R} 410 \mathrm{~A}$ in a horizontal micro-fin tube with saturation temperature ranging from $-30{ }^{\circ} \mathrm{C}$ to $10{ }^{\circ} \mathrm{C}$; heat flux values ranging from 1.0 to $20 \mathrm{~kW} / \mathrm{m}^{2}$; mass flux values ranging from 25 to $300 \mathrm{~kg} / \mathrm{m}^{2} \mathrm{~s}$; with a vapor quality that ranged between 0.1 and 1.0. A new method to derive the heat transfer coefficient was presented in Wojtan et al. [4 , 5]; Olivier et al. [6] investigated tube side condensation of several tubes (smooth tube, helical micro-fin tube, and herringbone tube) using various 
refrigerants (R22, R134A, R407C). The result showed that $x_{A I}$ (a transform criterion of flow pattern from annular flow to intermittent flow) of the herringbone tube was much smaller than a smooth tube; and for a micro-fin tube it decreased slightly. Compared with a smooth tube, the pressure drop of the herringbone tube was $80 \%$ higher; while only $27 \%$ higher than a micro-fin tube. The author's group [7-9] intensively studied the heat transfer characteristics of evaporation in micro/mini-channels. Li and $\mathrm{Wu}$ [7] presented a more accurate correlation for evaporative HTC by taking the combined effects (a non-dimensional parameter $\mathrm{Bo} \cdot \mathrm{Re}_{l}^{0.36}$ ) of liquid Reynolds number and Bond number into account, in the regime of $\operatorname{Re}_{l}<2000$ and $\mathrm{Bo}<3$. Subsequently, a new criterion for adiabatic twophase pressure drop is also established by using Bound number and liquid Reynolds number to modify the Chisholm parameter in $\mathrm{Li}$ and $\mathrm{Wu}[8]$; and the Chisholm parameter was distinguished into three ranges by the Bond number; when $\mathrm{B} o<1.5$, the surface tension dominates the pressure drop; when $\mathrm{Bo}>11$, surface tension can be ignored; and when $1.5<\mathrm{Bo}<11$, surface tension, inertia and viscous forces are all important in the micro/mini-channels. $\mathrm{Wu}$ and $\mathrm{Li}$ [9] proposed a saturated critical heat flux correlation by combining the boiling number, length-to-diameter ratio and outlet quantity, which can predicts almost $97 \%$ of non-aqueous data (except R12 data) and $94 \%$ of the water data with in the $\pm 30 \%$ error band. Kattan et al. [10] updated the flow pattern map by editing and redefining the transition curves. Methods to distinguish different flow regimes are provided in Kattan et al. [10]. Liebenberg and Meyer [11 , 12] observed the refrigerant condensation flow regimes in enhanced tubes and evaluated the effect of enhancement on heat transfer coefficients and pressure drops for mass flux values that ranged from 300 to $800 \mathrm{~kg} / \mathrm{m} 2 \mathrm{~s}$; at a saturation temperature 313.15K. Comparing condensation conditions of the enhanced tubes evaluated in $[11,12]$ with smooth and micro-fin tubes, the two enhanced tubes produced an earlier transition from annular flow to intermittent flow. Moreover, the heat transfer coefficient (HTC) of the enhanced tubes is approximately 1.7 times of the smooth tube; with an $80 \%$ increase in pressure drop. A detailed review of condensation heat transfer and pressure drop characteristics of enhanced tubes are also 
presented by Dalkilic and Wongwises [13].

Only recently have condensation and evaporation empirical models been developed for single enhancement unit in tube side, such as rough surfaces, extended surfaces, and displaced insert swirl flow. Gregorig [14] discussed surface tension effects on 2-D enhanced condensation tubes, all models developed in the current study begin to take surface tension into account. Belghazi et al. [15] developed a theoretical condensation model for a complicated 3-D tube; whose geometry changes in both the axial and circumferential directions.

The author's group [16] conducted studies to evaluate the tube side convective condensation and evaporation heat transfer performance using three different refrigerants in three equivalent diameter copper tubes (a smooth tube, a herringbone tube and a 3-D 1EHT tube; with inner diameter $11.5 \mathrm{~mm})$. Results indicated that the condensation heat transfer of the herringbone tube is 2 - 3 times larger than that of smooth tube and condensation heat transfer coefficient of the 1EHT tube is 1.3 1.95 times that of the smooth tube. Better performance of herringbone tube than EHT tube is mainly because of the larger surface area increase and efficiency of liquid drain due to the surface tension produced by the micro-channels between different fins. While for evaporation, their results indicated that EHT tube provided the best evaporation heat transfer coefficient (HTC); with the herringbone tube only producing a slightly higher evaporation HTC when compared to a smooth tube. Unlike the 1EHT tube in [16], heat transfer surface area enhancement ratio of 2EHT tubes tested in this study is much smaller. Vicente et al. [17] studied the heat transfer and friction factors of ten helically dimpled tubes and presented five performance evaluation criteria. However, they did not study the heat transfer and pressure drop performance under two phase flow conditions. In general, literature lacks two-phase flow studies and correlations to predict the heat transfer coefficient and pressure gradient for many newly developed enhanced tubes; currently there is no explanation of the physical mechanism of the 2EHT tubes evaluated in this study. 
The two tubes (2EHT-1 and 2EHT-2) evaluated in this study are 3-D enhanced tubes. They have different configurations than previously investigated enhanced heat transfer tubes and have different surface characteristics from those Vipertex 1EHT tubes investigated in previous studies [1719]. As shown in Fig. 1, the 2EHT tube surfaces are more of a hybrid surface that includes many small, regularly spaced dimples with periodic grooves on both the inside and outside of the tube surfaces. Height parameters, actual surface area and various measured parameters are clearly reported in Fig. 2. The 2EHT-1 tube has a lighter (not as prominent) secondary, small dimple enhancement than what is used in the 2EHT-2 tube. These surface enhancements increase surface area; aid in the local flow separation and boundary layer disruption; produce a higher density of nucleation sites; and produce a higher level of turbulence intensity (caused by the primary and secondary enhancements). Both of these enhanced tubes would lead to an increase in both the condensation and evaporation heat transfer coefficient. The technique used to enhance heat transfer for these tubes provides a promising method to further design project of two-phase heat exchangers.

The purpose of this investigation is to provide an experimental study of condensation and evaporation heat transfer and pressure drop inside the 2EHT-1 and 2EHT-2 enhanced tubes. Results are then compared to a smooth tube that has an equivalent inner diameter. Fig. 1 provides surface details produced using a 3-D Non-Contact Profilometer of the two enhanced tubes (2EHT-1 and 2EHT-2); height parameters for both tubes are presented in Fig. 2. Mass flux values ranged up to 300 $\mathrm{kg} / \mathrm{m}^{2} \mathrm{~s}$. As discussed in $[18,19]$, surface tension plays an important effect in micro-fin tubes at mass flux values considered in this study and the same effect is expected here. In enhanced tube with minichannels, surface tension forces contribute to drainage and transportation of the liquid film. This contribution is inversely proportional to the film thickness. 


\section{Experimental Details}

\subsection{Experimental Apparatus}

Fig. 3 (a) illustrates the flow diagram and the experimental apparatus used in this study. The experimental apparatus is composed of three loops: (i) refrigerant circulation loop (including the test section); (ii) water circuit - used to control the outlet quality of the tube being tested by changing the water inlet temperature; (iii) condensation section - used to sub-cool the refrigerant coming from the outlet of test section. The inlet quality of test section is controlled by an electric heater.

Temperatures are controlled by PID controller in a thermostatic bath. Components of the refrigerant loop include: 50 L reservoir tank, digital gear pump equipped with a frequency converter, needle valve, Coriolis Effect mass flow meter (with an accuracy of $\pm 0.1 \%$ of reading), preheating section, test section, condenser, sight glasses and several valves. In order to control the mass flow rate through the refrigerant cycle accurately, a needle valve is used. The Coriolis Effect mass flow meter (located between the pump and preheating section) is used to measure the refrigerant mass flow rate. Sub-cooled refrigerant coming from the reservoir (through the pump) is heated to the required outlet quality (calculated from the energy balance at the preheating section) by changing the voltage and current of electric heater. Refrigerant then enters the test section and will be condensed or evaporated. Subsequently, the two-phase refrigerant is sub-cooled to approximately $8{ }^{\circ} \mathrm{C}$ below the saturation temperature at the tested pressure. Temperatures necessary in order to determine the thermodynamic parameters of the fluid are obtained using Platinum 100 Resistance Temperature Detectors (RTD-100, with a calibrated accuracy of $\pm 0.1 \mathrm{~K}$ ); they are installed at the inlet and outlet of the test section. Two absolute pressure transducers (with an accuracy of $0.075 \%$ of the full scale) are used to measure the pressure at the inlet and outlet of the test section; a differential pressure transducer (with an accuracy of $0.075 \%$ of the full scale) is installed between the inlet and outlet of test section in order to obtain the total pressure drop of the tubes being tested. Water temperature of 
the water circuit are measured using platinum RTD-100s and an electromagnetic flow meter (with an accuracy of $\pm 0.2 \%$ of reading) is used to measure mass flow rate.

Fig. 3 (b) provides details on the experimental test section (a two-meter-long, tube-in-tube, countercurrent flow heat exchanger). Tubes evaluated are installed as the inner tube in the heat exchanger. Both 2EHT tubes have the same outer diameter (OD) of $12.7 \mathrm{~mm}$, inner diameter (ID) of $11.5 \mathrm{~mm}$ with the surface details being shown in Fig. 1 and Fig. 2. As is shown in Fig. 3 (b), the refrigerant being used, R410A, is condensed or evaporated in the test tube as water flows countercurrent in the annulus of the test section. Temperature, pressure and differential pressure are measured simultaneously during the test process. The measured saturation temperatures are in good agreement (within $\pm 0.3 \mathrm{~K}$ ) with the referenced saturation temperature that is indirectly obtained from the measured inlet pressure. Average heat transfer coefficients rather than local values are measured due to the design of test section and the limitation of measuring points. Pressure drop is limited to the overall pressure drop across the two-meter tube. Fig. 3 (c) details the cross sectional view of test tube and details the method of insulation used in the test section. In order to minimize heat loss through the outer side of the annulus, the entire test section (including the tube-in-tube heat exchanger) is installed in a larger PVC tube. It is then insulated using an insulation foaming agent that provides an insulation layer (approximately $80 \mathrm{~mm}$ thick) between the outer wall of the double tube heat exchanger and inner wall of the PVC tube. Total heat loss of the test section is controlled to less than $\pm 5 \%$; this ensure that the heat loss in the test section is an insignificant factor to the final results.

\subsection{Experimental Heat Transfer Test Conditions}

Tube side condensation and evaporation heat transfer characteristics are studied using refrigerant $\mathrm{R} 410 \mathrm{~A}$; at the saturation temperature $45^{\circ} \mathrm{C}$ (condensation) and $6{ }^{\circ} \mathrm{C}$ (evaporation); for mass flux values that range from 60 to $260 \mathrm{~kg} / \mathrm{m}^{2} \mathrm{~s}$ (condensation) and 60-175 kg/m ${ }^{2} \mathrm{~s}$ (evaporation); with a quality variation for condensation that ranges from 0.9 (inlet) to 0.2 (outlet) and for 
evaporation 0.2 (inlet) to 0.9 (outlet). During the experiment, inlet/outlet quality and saturation temperature were fixed; while mass flux and heat flux varied. Mass flux was determined by using the inner tube cross sectional area; heat flux was then calculated using the enhanced tubes surface area that is obtained from a 3-D profilometer (results shown in Fig. 2). Data was collected over 400 seconds (averaging 20 points, each with interval of 20 seconds), when deviations of temperature were below $0.1 \mathrm{~K}$; deviations of pressure below $10 \mathrm{kPa}$; and deviations of quality were below 0.05 .

\subsection{Uncertainty Analysis}

Uncertainty of the dependent quantities can be calculated using the follow equations based on error delivering theory. Experimental uncertainties for all measured parameters are summarized in Table 1. Uncertainty of the heat transfer rate for the test section is derived from the energy balance detailed in Eq. (1).

$$
\xi\left(Q_{w}\right)=\sqrt{\frac{\sigma_{W_{w, \text { exp }}^{2}}^{2}}{W_{w, \text { exp }}^{2}}+2 \frac{\sigma_{T}^{2}}{\left(T_{w, \exp , \text { in }}-T_{w, \exp , \text { out }}\right)^{2}}}
$$

Eq. (2) provides the basis for the calculation of the uncertainty in the mass flux.

$$
\xi\left(G_{r e f}\right)=\frac{1}{G_{r e f}} \sqrt{\left(\frac{\partial G_{r e f}}{\partial W_{r e f}}\right)^{2} \sigma_{W_{r e f}}^{2}+\left(\frac{\partial G_{r e f}}{\partial d_{i}}\right)^{2} \sigma_{d_{i}}^{2}}
$$

Combined with the conversion relation between mass flow rate and mass flux, Eq. (2) can be reduced to,

$\xi\left(G_{r e f}\right)=\sqrt{\xi^{2}\left(W_{r e f}\right)+4 \xi^{2}\left(d_{i}\right)}$

Similarly, the uncertainty of vapor quality can be given as presented in Eq. (4).

$$
\xi\left(x_{i n}\right)=\frac{1}{x_{i n}} \sqrt{\left(\frac{\partial x_{i n}}{\partial V}\right)^{2} \sigma_{V}^{2}+\left(\frac{\partial x_{i n}}{\partial I}\right)^{2} \sigma_{I}^{2}+\left(\frac{\partial x_{i n}}{\partial W_{r e f}}\right)^{2} \sigma_{W_{r e f}}^{2}+\sum\left(\left(\frac{\partial x_{i n}}{\partial T_{j}}\right)^{2} \sigma_{T}^{2}\right)}
$$

The uncertainly of refrigerant side heat transfer coefficient is determined using Eq. (5). 
$\xi\left(h_{r e f, i}\right)=\sqrt{\xi^{2}\left(A_{i}\right)+\xi^{2}(P)}$

Where $P=\frac{L M T D}{Q_{w}}+\frac{1}{h_{w, o} A_{o}}+\frac{\ln \left(d_{o} / d_{i}\right)}{2 \pi L \cdot k}$

\section{Data reduction}

The data information obtained by data acquisition system was reduced in order to determine the tube-side heat transfer coefficient. Total heat transfer rate in the test section was determined using an energy balance for the annulus, and is given by

$$
Q_{w}=c_{p, \exp } W_{w, \exp }\left(T_{w, \exp , \text { in }}-T_{w, \exp , \text { out }}\right)
$$

Where $c_{p, \exp }, W_{w, \exp }, T_{w, \exp , \text { in }}$ and $T_{w, \exp , \text { out }}$ are the annulus specific heat, annulus water flow rate, and inlet water / outlet water temperature of test sections, respectively. In this experiment, the insulation layer around the test section was made from a foaming agent and is shown in Fig. 3 (c). The insulation layer was designed to be thick enough to minimize the heat loss due to temperature difference between annulus fluid and the external environment; producing a heat loss that is less than $5 \%$; this losses can be neglected.

Inlet vapor quality, $x_{i n}$, was determined from the energy balance in the preheating section. Total heat, $Q_{\text {pre }}$, is given in Eq. (7) and is the heat transferred in the preheating section; this involves two forms of heat, sensible heat $Q_{\text {sens }}$ and latent heat $Q_{\text {lat }}$.

$$
Q_{\text {pre }}=\lambda \cdot V I=Q_{l a t}+Q_{\text {sens }}
$$

Where,

$$
\begin{aligned}
& Q_{\text {sens }}=c_{p, l, r e f} W_{r e f}\left(T_{s a t}-T_{r e f, p r e, i n}\right) \\
& Q_{l a t}=W_{r e f} h_{l v} x_{i n}
\end{aligned}
$$

With

$$
x_{i n}=\frac{\lambda \cdot V I}{W_{r e f} h_{l v}}-\frac{c_{p, l, r e f}}{h_{l v}}\left(T_{s a t}-T_{r e f, p r e, i n}\right)
$$


Additionally, $\lambda, V, I$ are the experimentally determined loss efficient of electric power (account for the heat loss to the environment and the heat conduction of the wire and tube), voltage and current; $c_{p, l, r e f}, W_{r e f}, T_{r e f, p r e, i n}$ are the corresponding parameters of refrigerant side (tube side); and $\boldsymbol{T}_{\text {sat }}$, $h_{l v}$ are the determined saturated temperature (taken form the average pressure of inlet pressure of the pre-heater) and the latent heat of vaporization of R410A (taken from the saturation temperature in the preheating section)respectively. All temperatures are obtained using platinum RTD-100s and are calibrated to an accuracy within $0.1 \mathrm{~K}$.

Outlet quantity, $x_{\text {out }}$, can be calculated using the following equation:

$x_{\text {out }}=x_{\text {in }} \pm Q_{w} /\left(W_{\text {ref }} h_{l v}\right)$

In Eq. (10), the addition operator (+) is used for evaporation conditions; while the negative operator (-) is used for condensation conditions. Log-mean temperature difference (LMTD) was determined by using the annulus side inlet and outlet water temperatures; and the tube side inlet and outlet refrigerant temperatures,

$$
L M T D=\frac{\left(T_{r e f, \exp , \text { out }}-T_{w, \exp , \text { in }}\right)-\left(T_{r e f, \exp , \text { in }}-T_{w, \exp , \text { out }}\right)}{\ln \left[\left(T_{r e f, \exp , \text { out }}-T_{w, \exp , \text { in }}\right) /\left(T_{r e f, \exp , \text { in }}-T_{w, \exp , \text { out }}\right)\right]}
$$

Where $T_{\text {ref,exp,in }}, T_{\text {ref,exp,out }}$ are the inlet and outlet refrigerant temperatures in the experimental test section, respectively. Since there is a pressure drop over the test section during condensation, the inlet refrigerant and outlet refrigerant temperatures are not equal to each other; temperatures $T_{\text {ref,exp,in }}$ and $T_{\text {ref,exp,out }}$ are measured using a Platinum RTD-100 installed at the inlet and outlet of the tested heat transfer tube (shown in Fig. 3 (b)). Based upon the properties of R410A and the high vacuum environment (less than $0.5 \mathrm{kPa}$, absolute pressure), it is reasonable to assume no tube side fouling resistance.

Tube side refrigerant heat transfer coefficient for in-tube condensation can be determined from the following resistance equation, 


$$
h_{r e f, i}=\frac{1}{A_{i}\left[\frac{L M T D}{Q_{w}}-\frac{1}{h_{w, o} A_{o}}-\frac{\ln \left(d_{o} / d_{i}\right)}{2 \pi L \cdot k}\right]}
$$

Where $k$ is the thermal conductivity of the tested tube wall; $d_{i}, d_{o}$ are the nominal inner and outer diameters of tested tube; and $A_{i}, A_{o}$ are the heat transfer areas of the refrigerant (tube side) and the annulus (water) side, respectively.

The heat transfer enhancement ratio for single phase flows on the water side can be easily obtained using Wilson plot. Previous investigators $[20,21]$ have shown that Wilson plot is an accurate method to predict the enhanced heat transfer ratio of enhanced or irregular shaped surfaces for single phase flow. For the two enhanced tubes (2EHT-1 and 2EHT-2) tested, the enhanced heat transfer ratios of 1.48 and 1.52 times that of a smooth tube are determined, respectively; this enhancement is the result of the dimples and grooves on the tube surface and results are detailed in Fig. 4.

Previous studies have showed that the Gnielinski [22] relation can accurately predict the tube side heat transfer coefficient for smooth tubes and is valid for $0.5<P_{r}<2000$ and $3000<\operatorname{Re}<5 \times 10^{6}$. During this experiment, the water Reynolds Number, Re, in annulus is controlled in this range, as is given in former section. Thus the annulus-side heat transfer coefficient, $h_{w, o}$, was calculated using the following relation from Gnielinski [22]

$$
h_{w, o}=C \cdot \frac{(f / 2)(\operatorname{Re}-1000) P_{r}}{1+12.7(f / 2)^{0.5}\left(P_{r}^{2 / 3}-1\right)}\left(\frac{\mu_{\text {bulk }}}{\mu_{\text {wall }}}\right)^{0.14} \frac{k_{w}}{d_{h}}
$$

Where the constant $\mathrm{C}$ is the heat transfer ratio of the enhanced surface tube compared with the smooth tube. The single phase results showed that $\mathrm{C}=1.48$ for $2 \mathrm{EHT}-1$, and $\mathrm{C}=1.52$ for $2 \mathrm{EHT}-2$. In Eq. (13) the property ratio $\left(\mu_{\text {bulk }} / \mu_{\text {wall }}\right)^{0.14}$ corrects for the viscosity variations and is evaluated at the bulk temperature and the wall temperature; property differences for this case amount to less than $1 \%$. 
Finally, $k_{w}$ is the thermal conductivity of the fluid (water) evaluated at the average of the inlet and outlet temperatures.

Eq. (14) gives the Fanning friction factor which was determined using the Petukhov correlation [23] and is valid over the range of $3000<\operatorname{Re}<5 \times 10^{6}$.

$$
f=(1.58 \cdot \ln \operatorname{Re}-3.28)^{-2}
$$

During flow condensation or evaporation, the measured two-phase flow pressure drop along the horizontal test tube was measured using a differential pressure transducer and can be expressed in Eq. (15) as the sum of four pressure drop terms: momentum component; frictional pressure drop; a component taking account of a sudden enlargement; and the final term accounting for a contraction,

$\Delta P=\Delta P_{m}+\Delta P_{f}+\Delta P_{S L}+\Delta P_{S C}$

The momentum pressure drop component due to the kinetic energy change of flow is predicted by Eq. (16),

$$
\Delta P_{m}=G_{r e f}^{2}\left\{\left[\frac{x^{2}}{\rho_{\nu} \varepsilon}+\frac{(1-x)^{2}}{\rho_{l}(1-\varepsilon)}\right]_{\text {out }}-\left[\frac{x^{2}}{\rho_{v} \varepsilon}+\frac{(1-x)^{2}}{\rho_{l}(1-\varepsilon)}\right]_{\text {in }}\right\}
$$

where $\rho_{v}, \rho_{l}$ are the density of the vapor phase and liquid phase respectively; $\varepsilon$ is the local void fraction defined as the ratio of cross-section area of vapor phase to the cross-section area of liquid phase. The local void fraction is given by Eq. (17) and can be accurately predicted by the drift flux model of Rouhani and Axelsson [24]; it is applicable for different flow regimes.

$\varepsilon=\frac{x}{\rho_{v}}\left[(1+0.12(1-x))\left(\frac{x}{\rho_{v}}+\frac{1-x}{\rho_{l}}\right)+\frac{1.18(1-x)\left[g \sigma\left(\rho_{l}-\rho_{v}\right)\right]^{0.25}}{G_{r e f} \rho_{l}^{0.5}}\right]^{-1}$

In Eq. (17), $x, \sigma, G_{r e f}$ are the vapor quality, surface tension, and total mass velocity of refrigerant.

The equations for sudden enlargement and sudden contraction pressure drops components [25] are given in Eq. (18) and Eq. (19). 


$$
\begin{aligned}
\Delta P_{S L} & =\frac{G^{2} \sigma(1-\sigma)}{\rho_{l}}\left[1+\left(\frac{\rho_{l}-\rho_{v}}{\rho_{v}}\right) x\right] \\
\Delta P_{S C} & =\frac{G^{2}}{2 \rho_{l}}\left[1+\left(\frac{\rho_{l}-\rho_{v}}{\rho_{v}}\right) x\right]
\end{aligned}
$$

It was determined that the momentum component was less than $10 \%$ of the entire pressure drop. Frictional pressure drop, that is a result of the wall friction and interface shear stress, dominates the flow resistance. All the thermal properties and transport properties in this study are referred to an universal software of refrigerant (REFPROP 8.0).

\section{Results and Discussion}

\subsection{Experimental Validity and Single-phase Heat Transfer}

Single phase heat transfer evaluation of all the tubes were performed in order to determine the heat transfer enhancement factor on the annuli (water) side of the enhanced tube during tube side condensation and evaporation testing. In addition, verification of the performance of the insulation of the test section was also performed. Single phase experiments were carried out using a sub-cooled refrigerant at a mass flow rate of $73 \mathrm{~kg} / \mathrm{h}$; with annuli (water) mass flow rates that ranged from 325 to $548 \mathrm{~kg} / \mathrm{h}$. Fig. 4 shows the advanced Wilson plot results of the $2 \mathrm{EHT}-1$ and $2 \mathrm{EHT}-2$ enhanced tubes. The enhancement factor of the water flow in the annulus for the 2EHT- 1 tube was determined to be 1.48 and 1.52 for the 2EHT-2 tube. Vicente et al. [17] confirmed this analysis method for such doubly enhanced tube studied in that evaluation. They experimentally studied the heat transfer and pressure drop performance of turbulent flow in 10 three-dimensional enhanced tubes that were made up of regularly helically dimpled tubes. They found that all dimpled tube presented higher HTC than smooth tube, and the deeper the dimple, the better the performance. Results from the error propagation theory show that in order to get an accurate enhanced factor, $\mathrm{C}$, conditions of the experiment need to be controlled as the resistance of the annuli side is much larger than that of the tube side resistance. The value of the enhanced factor is affected by several factors, including surface 
area; secondary flows produced as a result of the surface roughness; thickness of the boundary layer; and turbulence intensity/mixing. Height of the enhancements and a slight increase in surface area are the only outer surface differences between the 2EHT-1 and 2EHT-2 enhanced tubes.

Heat balance of the test section is illustrated in Fig. 5; indicating that the heat loss that occurs during the experiment is minimal and is non-significant since for all conditions results are within a heat loss band that is less than $4 \%$. Fig. 6 compares experimental results for a smooth tube to predicted values using two, well accepted, single phase heat transfer coefficient correlations. As is shown in Fig. 6, the Gnielinski correlation [22] can predict all data points within a deviation band that is less than $4 \%$; and the Dittus-Boelter correlation [26] produces an approximate deviation band of 7 9\%. Gnielinski [22] provides a more accurate prediction as mass flux or Reynolds number increases.

Fig. 7 details the results using the 2EHT-1 tube for several trials that took place within three weeks, Good agreement is seen over the mass flux range of 90 to $180 \mathrm{~kg} / \mathrm{m}^{2} \mathrm{~s}$; evaporation quality range $0.2-0.9$; with a saturation temperature of $6{ }^{\circ} \mathrm{C}$. Each of the experimental conditions was tested every five days using the R410A refrigerant.

\subsection{Condensation Heat Transfer}

Condensation of R410A in two horizontal three dimensional surface enhanced tubes (2EHT-1 and 2EHT-2, both with a nominal OD of $12.7 \mathrm{~mm}$ and ID of $11.5 \mathrm{~mm}$ ) were evaluated and performance is compared to a smooth tube of the same dimensions. Experimental runs were controlled at a saturation temperature $45{ }^{\circ} \mathrm{C}$; with a mass flux that ranged from 80 to $260 \mathrm{~kg} / \mathrm{m}^{2} \mathrm{~s}$; with an inlet quality of 0.9 and an exit quality of 0.2 . Average values (over the two-meter long tested tubes) of the heat transfer coefficient are presented in Fig. 8. Here it can be seen that the average heat transfer coefficient increases with increasing mass flux; however the rate of increase varies among tubes. 
For the smooth tube, the heat transfer coefficient increases slightly when the mass flux is less than $200 \mathrm{~kg} / \mathrm{m}^{2} \mathrm{~s}$, with the vapor quality ranging from 0.9 to 0.2 and the $2 \mathrm{EHT}$ tube performance is different. Driving temperature difference (LMTD) range for the various tube runs were: 6.89 - 24.27 ${ }^{\circ} \mathrm{C}$ (smooth), $7.56-23.63{ }^{\circ} \mathrm{C}(2 \mathrm{EHT}-1)$ and $6.10-21.1{ }^{\circ} \mathrm{C}$ (2EHT-2). The corresponding heat transfer rates ranges are $10.55-34.61 \mathrm{~kW} / \mathrm{m}^{2}$ (smooth), $11.71-36.66 \mathrm{~kW} / \mathrm{m}^{2}$ (2EHT-1) and 10.95 $34.57 \mathrm{~kW} / \mathrm{m}^{2}$ (2EHT-2 ); with mass flux ranges $87.87-267.58 \mathrm{~kg} / \mathrm{m}^{2} \mathrm{~s}, 87.48-262.19 \mathrm{~kg} / \mathrm{m}^{2} \mathrm{~s}$ and $81.25-257.17 \mathrm{~kg} / \mathrm{m}^{2} \mathrm{~s}$, respectively. Condensation stratified flows (lower mass velocity; including stratified-wavy flows) are formed when the saturated vapor enters the condenser tube at low mass flux (lower than $200 \mathrm{~kg} / \mathrm{m}^{2} \mathrm{~s}$ ). This transition criteria is discussed by El Hajal. [27] and shown in Eq. (20).

$G_{\text {wavy }}=\left\{\frac{16 A_{V d}^{3} g d \rho_{l} \rho_{v}}{x^{2} \pi^{2}\left(1-\left(2 h_{L d}-1\right)^{2}\right)^{0.5}}\left[\frac{\pi^{2}}{25 h_{L d}^{2}} \cdot\left(\frac{W e}{F r}\right)_{l}^{-1.023}+1\right]\right\}^{0.5}+50-75 e^{-\left(x^{2}-0.97\right) / x(1-x)}$

Smooth tube condensation results using R410A is shown in Fig. 8. It can be seen that the HTC increases slightly for mass flux values lower than $200 \mathrm{~kg} / \mathrm{m}^{2} \mathrm{~s}$ and then the HTC increases more rapidly for mass flux values over $200 \mathrm{~kg} / \mathrm{m}^{2} \mathrm{~s}$. Smooth tube heat transfer coefficients have demonstrated a different tendency than the 2EHT tubes. For mass flux lower than $200 \mathrm{~kg} / \mathrm{m}^{2} \mathrm{~s}$, saturated vapor entered the condenser tube and a liquid layer formed in the bottom of the smooth tube. A gravity controlled condensation mechanism dominates the heat transfer progress. For a mass flux $\mathrm{G}>220 \mathrm{~kg} / \mathrm{m}^{2} \mathrm{~s}$, the heat transfer coefficient in the smooth tube increases more rapidly at these rates than at lower mass flux values. The larger HTCs may be due to a larger shear force that forms between the liquid phase and the vapor phase. For a mass flux close to $250 \mathrm{~kg} / \mathrm{m}^{2} \mathrm{~s}$, the shear force begins to dominate the flow regime; leading to the formation of a thin liquid film around the tube that produces a larger amount of liquid film washing the top of the tube. This transition boundary is also implied in Wu et al. [18]. 
Unlike the smooth tube, the two enhanced tubes (2EHT-1 and 2EHT-2) produce a different variation of heat transfer characteristics. Both of the 2EHT tubes demonstrate a similar variation of the HTC as a function of mass flux; producing uniform increase of HTC with increases to the mass flux. Extended surfaces are produced from an assembly of longitudinal grooves and dimples on both sides of the tube surface (as shown in Fig. 1). The repeated formation of the flute shape grooves around the circumference provides the possibility to redistribute the liquid film during an autobalance process that takes place among the body force, shear force and surface tension for the higher mass flux values of this experiment. Furthermore, the flute shape of the 2EHT-1 and 2EHT-2 tubes promotes condensate drainage from the surface by the surface tension forces. For low mass flux values, the vapor phase condenses on the top of the tube side surface wrinkle and then as a result of the surface tension, the liquid film moves to the grooves. As mass flux increases, the heat transfer coefficient increases as the shear force begins to dominate the flow. In addition, the extended surfaces, the rough surfaces of the 2EHT tube (due to the small dimples) produce additional disturbances and mixing, i.e. creating secondary flows near the boundary layer. This produces a larger HTC during the convective flow process of the liquid film. All of these factors contribute to a larger (when compared to a smooth tube) condensation HTC in the 2EHT tubes; this is clearly shown in Fig. 8. For higher mass flux rates, it can be seen that the heat transfer coefficients are linearly related to mass flux. At these higher flows the drainage channels are flooded. The only difference between the 2EHT-1 and 2EHT-2 tubes is the depth of dimple enhancement (on the outer surface) or embossments (on the inner surface). Thus, the HTC curves of both of the 2EHT tubes demonstrate the same tendency and produce only a slight increase in the condensation HTC for the 2EHT-2 tube.

Frictional pressure drop is given in Fig. 9 for the three tested tubes; with R410A condensation in a two-meter-long horizontal tube, at a saturation temperature of $45^{\circ} \mathrm{C}$. Frictional pressure drop is calculated by subtracting the momentum component, sudden enlargement and sudden contraction due to the connection of different tube diameters between the tested tube and the experimental tube; 
details are given in Eq. (18) - (19). A very small difference can be seen between the two 2EHT tubes; this leads to a small difference in frictional pressure drop. This is a resulted of the similar geometric structures (there is only a slight difference in dimple / embossment depth). Fig. 9 shows that the pressure drop of the 2EHT tubes are approximately $1.06-1.68$ times the pressure drop found in a smooth tube. Previous pressure drop correlations applied to the 2EHT tube geometry predict values that are under predicted; similar findings are found in Vicente et al. [17]. Their experimental data showed that the frictional pressure drop decreased as the depth of dimples increased.

\subsection{Evaporation heat transfer}

Fig. 10 compares the test results of the tube side evaporation heat transfer coefficient with that of a geometrically similar smooth tube at the saturation temperature $6{ }^{\circ} \mathrm{C}$; with quality ranging from 0.2 to 0.9 . Due to the experimental limitation of pressure drop and the frequency of the digital gear pump (maximum frequency $50 \mathrm{~Hz}$ ), the range of mass flux was limited to $80-200 \mathrm{~kg} / \mathrm{m}^{2} \mathrm{~s}$ for the 2EHT tubes. Fig. 11 provides a comparison of the evaporation frictional pressure drop of the 2EHT tubes and a smooth tube using R410A. For evaporation, the pressure drop due to momentum makes up $6-8 \%$ of the pressure drop for the smooth tube, $2.3-3.1 \%$ for 2EHT-1 and $3.4-4.0 \%$ for the 2EHT-2 tubes. Unlike the condensation conditions, frictional pressure drop of evaporation of the 2EHT-1 tube presents an obvious difference when compared to the 2EHT-2 tube. A reduced momentum component pressure drop and an increased frictional pressure drop component can be seen as difference between the 2EHT-1 tube and the 2EHT-2tube. An attempt to compare the test results with available correlations was made; however no previous correlation can accurately predict the results of the 2EHT tubes. Performance evaluation factor (PF) for the 2EHT tubes is presented in Fig. 12; PF (for the 2EHT tubes) is much larger than the ratio of surface area increase (when it is compared to a plain tube; 2EHT surface area details are given in Fig. 2). When compared to a smooth tube, the surface structure of the 2EHT tubes (dimple / embossment enhancements and grooves) creates many turbulent mixing regions and produces a different local temperature 
distribution in the R410A liquid film. The top of the flute and the secondary enhancements extend into the liquid film producing a higher rate of heat flowing from the inner tube wall to the liquid film near the boundary layer. Heat flux (for tube side evaporation of R410A) of the 2EHT-1 tube ranges from 17.88 to $40.01 \mathrm{~kW} / \mathrm{m}^{2}$, and 20.71 to $43.81 \mathrm{~kW} / \mathrm{m}^{2}$ for the $2 \mathrm{EHT}-2$ tube; when compared to a smooth tube where the values are 15.26 to $29.53 \mathrm{~kW} / \mathrm{m}^{2}$; for a mass flux ranging from 85 to 200 $\mathrm{kg} / \mathrm{m}^{2} \mathrm{~s}$.

Minimum inlet quality was controlled to 0.2 so as to avoid sub-cooled boiling at the inlet section of test tubes; the start region of the test conditions were constrained to nucleate boiling in order to reduce partial boiling regions since a lower HTC was found during the experiment when the inlet or outlet was sub-cooled. Additional details that define this boundary can be found in Dengler and Addoms [28]; the required heat flux to initiate the onset of nucleate boiling is determined as follows,

$q_{O N B}=\frac{49 B h_{l o}^{2}}{k_{l} X_{t t}}$

Where, $B=\frac{2 \sigma T_{\text {sat }}\left(\rho_{l}-\rho_{v}\right)}{h_{l v} \rho_{l} \rho_{v}}$

Enhanced ratio results for the two 2EHT tubes are very similar; and are determined from the surface structure details presented in Fig. 2. Surface areas of the two EHT tubes are not very different from each other; therefore the structure of the nucleation sites are not significantly different. Since the heat flux or the wall temperature was set in order to initiate nucleate boiling, the overall heat transfer coefficient is mainly determined from the heat transfer rate of phase change for the given mass flux range; with HTC values of the 2EHT tubes approximately $1.15-1.43$ (2EHT-1 tube) and $1.11-1.39$ (2EHT-2 tube) times of the smooth tube. 


\subsection{Performance evaluation}

Performance factor, PF, is a non-dimensional parameter and that is defined in Eq. (23) as the ratio of the average HTC (enhanced / smooth) multiplied by the heat transfer surface area ratio (smooth / enhanced).

$$
P F=\frac{h_{E H T}}{h_{s}} \cdot \frac{A_{s}}{A_{E H T}}
$$

Fig. 12 shows the condensation and evaporation heat transfer performance evaluation of R410A inside the 2EHT tubes. Fig. 12 (a) presents condensation performance factor results over the range of mass flux from 70 to $150 \mathrm{~kg} / \mathrm{m}^{2} \mathrm{~s}$. At lower values of mass flux, PF may be smaller than unity, while the performance factors remain steady for mass flux values that range from 150 to 257 $\mathrm{kg} / \mathrm{m}^{2} \mathrm{~s}$. Over the entire range, the PF of the 2EHT- 2 tube is larger than the PF of the 2EHT -1 tube.

Performance factors for evaporation in the 2EHT tubes are shown in Fig. 12 (b) and are much larger than unity over the mass flux range evaluated. Unlike condensation results, the two 2EHT tubes seem to present similar PFs when the mass flux is below $150 \mathrm{~kg} / \mathrm{m}^{2} \mathrm{~s}$; however for mass flux values larger than $150 \mathrm{~kg} / \mathrm{m}^{2}$ s the 2EHT-1 tube produces larger PFs.

In summary, the 2EHT tubes produce excellent overall performance for evaporation for the mass flux range considered, with the best performance occurring for $\mathrm{G}>150 \mathrm{~kg} / \mathrm{m}^{2} \mathrm{~s}$. The two 2EHT tubes produce steadily increasing HTC performance when compared to the performance of smooth tubes for $\mathrm{G}>150 \mathrm{~kg} / \mathrm{m}^{2} \mathrm{~s}$.

\section{Conclusions}

An experimental study of the convective condensation and evaporation performance of two enhanced surface heat transfer tubes and a smooth tube was carried out at the saturation temperatures of $45^{\circ} \mathrm{C}$ and $6^{\circ} \mathrm{C}$. Frictional pressure drop and mean heat transfer coefficients were presented, with the following conclusions being made:

(1) Tube side condensation and evaporation heat transfer characteristics of the 2EHT tubes and a smooth tube were presented. For condensation, 2EHT-2 tube produces a higher HTC than the 
2EHT-1 tube; for evaporation, the two 2EHT tubes produces approximately the same HTC for a mass flux, $\mathrm{G}<150 \mathrm{~kg} / \mathrm{m}^{2} \mathrm{~s}$ and the 2EHT-1 tube produces a higher HTC for G $>150 \mathrm{~kg} / \mathrm{m}^{2} \mathrm{~s}$.

(2) Pressure drop characteristic of the two 2EHT tubes have also been studied experimentally. For evaporation, pressure drop component of momentum part of the smooth tube is much larger than that of two 2EHT tubes. Higher frictional pressure drop is found during experimental runs of the 2EHT tubes. A conjecture that surface enhancements (embossments / dimples and grooves) can change the relative magnitude of sub-pressure component (momentum part and frictional part) during the energy transfer process.

(3) The advanced Wilson plot is a promising method for investigating double-surface enhanced tubes, and the Gnielinski correlation [18] can accurately predict the HTC of the annuli water side.

(4) The 2EHT tubes both produce a good PF for both evaporation and condensation; the 2EHT tubes presents the potential to be a very good tube for evaporation uses.

\section{ACKNOWLEDGMENTS}

This work is supported by the National Science Foundation of China (51210011) and National Science Foundation of Zhejiang Province, China (LZ13E060001). 


\section{References}

[1] R.L. Webb, N.H. Kim, Principles of Enhanced Heat Transfer, second ed., Taylor \& Francis Group, New York, 2005.

[2] A. Cavallini, G. Censi, D. Del Col, Condensation inside and outside smooth and enhanced tubes

— a review of recent research, International Journal of Refrigeration 26 (2003) 373-392.

[3] P. Rollmann, K. Spindler, New models for heat transfer and pressure drop during flow boiling of R407C and R410A in a horizontal micro-fin tube, International Journal of Thermal Sciences 103 (2016) 57-66.

[4] L. Wojtan, T. Ursenbacher, J. R. Thome, Investigation of flow boiling in horizontal tubes: Part I - A new diabatic two-phase flow pattern map, International Journal of Heat and Mass Transfer 48 (2005) 2955-2969.

[5] L. Wojtan, T. Ursenbacher, J. R Thome, Investigation of flow boiling in horizontal tubes: Part II-Development of a new heat transfer model for stratified-wavy, dry-out and mist flow regimes, International Journal of Heat and Mass Transfer 48 (2005) 2970-2985.

[6] J. A. Olivier, L. Liebenberg, J. R. Thome, J. P. Meyer, Heat transfer, pressure drop, and flow pattern recognition during condensation inside smooth, helical micro-fin, and herringbone tubes, International Journal of Refrigeration 30 (2007) 609-623.

[7] W. Li, Z. Wu, A general correlation for evaporative heat transfer in micro/mini-channels, International Journal of Heat and Mass Transfer 53 (2010) 1778-1787.

[8] W. Li, Z. Wu, A general correlation for adiabatic two-phase pressure drop in micro/mini-channels, International Journal of Heat and Mass Transfer 53 (2010) 2732-2739.

[9] Z. Wu, W. Li, S. Ye, Correlations for saturated critical heat flux in micro-channels, International Journal of Heat and Mass Transfer 54 (2011) 379-389. 
[10] N. Kattan, J. R. Thome, D. Favrat, Flow boiling in horizontal tubes. Part 3: development of a new heat transfer model based on flow patterns, Heat Transfer 120 (1) (1998) 156-165.

[11] L. Liebenberg, J. P. Meyer, A Review of Flow Pattern-Based Predictive Correlations during Refrigerant Condensation in Horizontally Smooth and Enhanced Tubes, Heat Transfer Engineering 29 (2008) 3-19.

[12] L. Liebenberg, J. P. Meyer, Refrigerant condensation flow regimes in enhanced tubes and their effect on heat transfer coefficients and pressure drops, Heat Transfer Engineering 29 (2008) 506-520. [13] A. S. Dalkilic, S. Wongwises, Intensive literature review of condensation inside smooth and enhanced tubes, International Journal of Heat and Mass Transfer 52 (2009) 3409-3426.

[14] R. Gregorig, Film condensation on finely rippled surfaces with consideration of surface tension, Z. Angew. Math. Phys 5 (1954) 36-49.

[15] M. Belghazi, A. Bontemps, C. Marvillet, Condensation heat transfer on enhanced surface tubes: experimental results and predictive theory, Journal of heat transfer 124 (2002) 754-761

[16] S.P. Guo, Z. Wu, David J. Kukulka, W. Li, Bengt Sundén. Condensation and evaporation heat transfer characteristics in horizontal smooth, herringbone and enhanced surface EHT tubes, International Journal of Heat and Mass Transfer 85 (2015) 281-291.

[17] Pedro G. Vicente, Alberto García, Antonio Viedma, Heat transfer and pressure drop for low Reynolds turbulent flow in helically dimpled tubes. International Journal of Heat and Mass Transfer 45 (2002) 543-553.

[18] Z. Wu, B. Sundén, L.Wang,W. Li, Convective condensation inside horizontal smooth and microfin tubes, Journal of Heat Transfer 136 (2014) 051504.

[19] Z. Wu, Y. Wu, B. Sundén, W. Li, Convective vaporization in micro-fin tubes of different geometries, Exp. Therm. Fluid Sci. (2013) 398-408.

[20] M.H. Kim, J.S. Shin, Evaporating heat transfer of R22 and R410A in horizontal smooth and micro-fin tubes, International Journal of Refrigeration 28 (2005) 940-948. 
[21] J. Fernández-Seara, A general review of the Wilson plot method and its modifications to determine convection coefficients in heat exchange devices, Applied Thermal Engineering 27 (2007) 2745-2757.

[22] V. Gnielinski, New Equations for heat and mass transfer in turbulent pipe and channel flow, Int. Chem. Eng. 16 (1976) 359-368.

[23] B. S.Petukhov, Heat transfer and friction in turbulent pipe flow with variable physical properties, Adv. Heat Transfer. 6 (1970) 503-564.

[24] S. Z. Rouhani, E. Axelsson, Calculation of void volume fraction in the subcooled and quality boiling regions, Int. J. Heat Mass Transfer. 13 (1970) 383-393.

[25] B. E. Richardson, Some problems in horizontal two-phase two-component flow, 1958 ANL5949.

[26] F. Dittus, L. Boelter, Publications on engineering, vol. 2, University of California at Berkeley, Berkeley, CA (1930) 433-461

[27] J. El Hajal, J.R. Thome, A. Cavallini, Condensation in horizontal tubes, part 1: two-phase flow pattern map, International Journal of Heat and Mass Transfer 46(18) (2003) 3349-3363.

[28] C. E. Dengler, J. N. Addoms, Heat transfer mechanism for vaporization of water in a vertical tube, Chemical Engineering Progress Symposium Series 52(18) (1956) 95-103. 


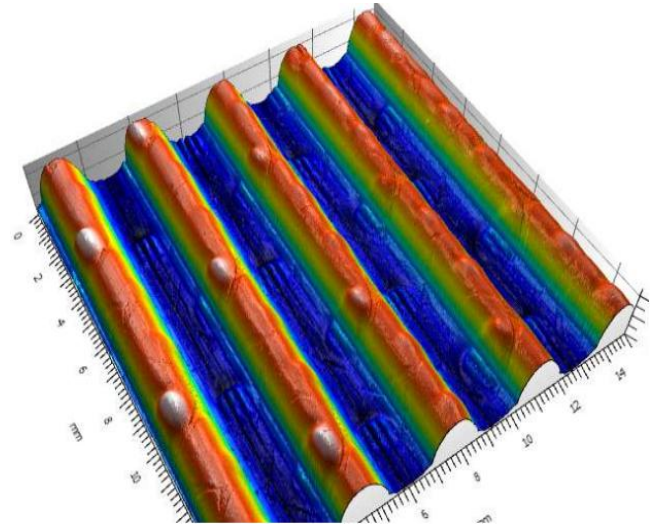

(a)

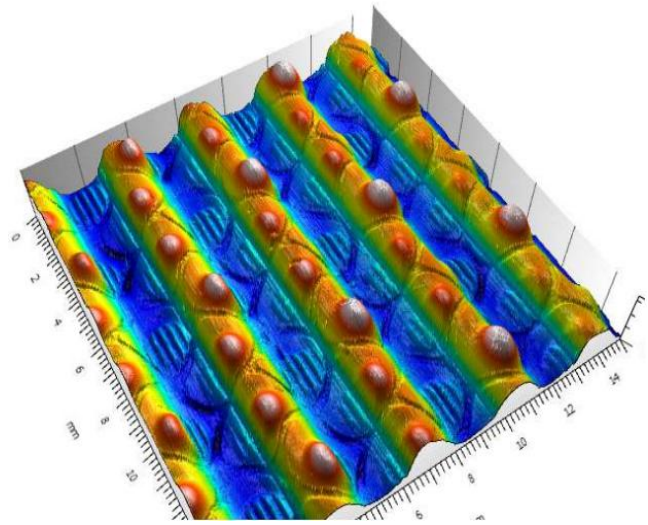

(b)

Fig. 1 Three Dimensional false color view of the surface enhancement structure of the (a) inner surface of the 2EHT-1 tube, (b) inner surface of the 2EHT-2 tube.

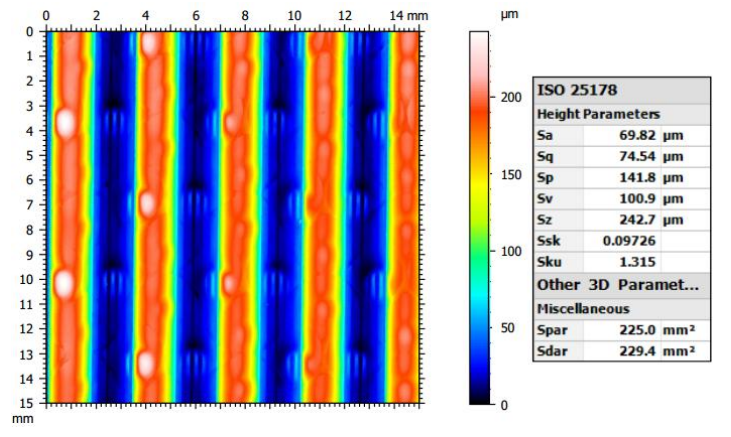

(a)

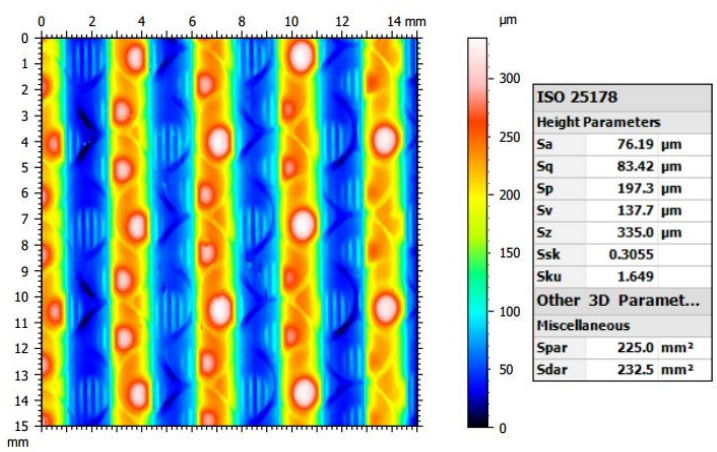

(b)

Fig. 2 Detailed parameters of the surface enhancement for the (a) 2EHT-1 tube, (b) 2EHT-2 tube 


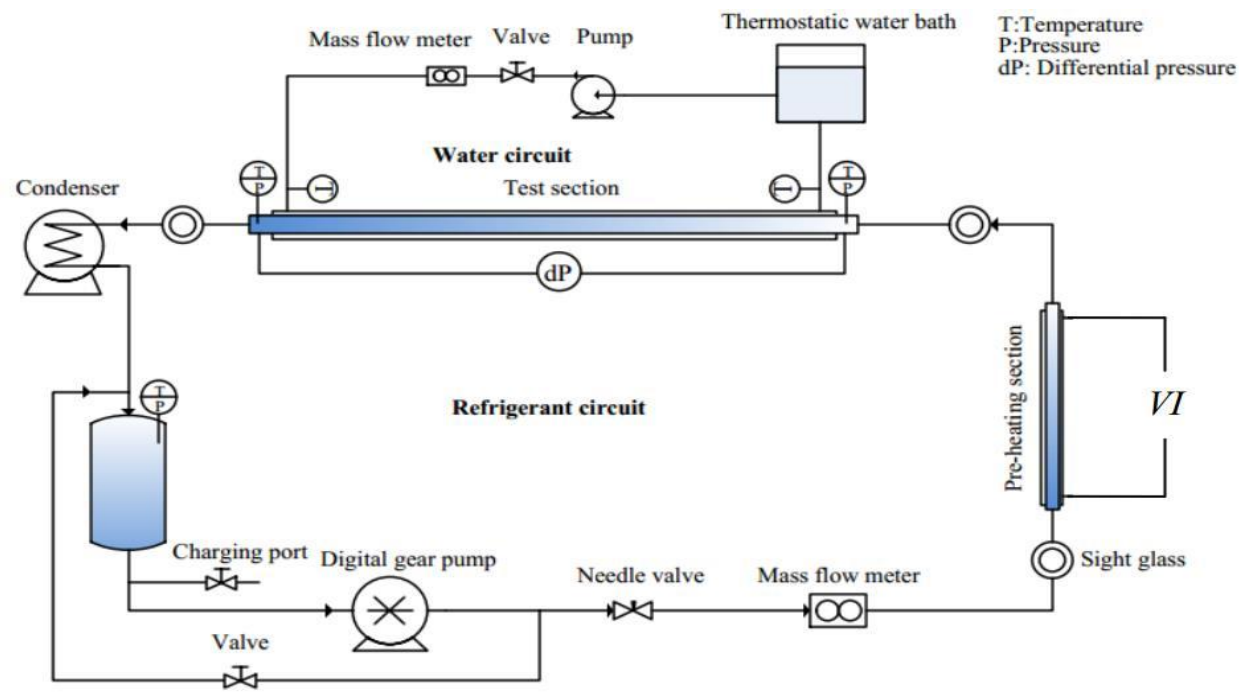

(a)

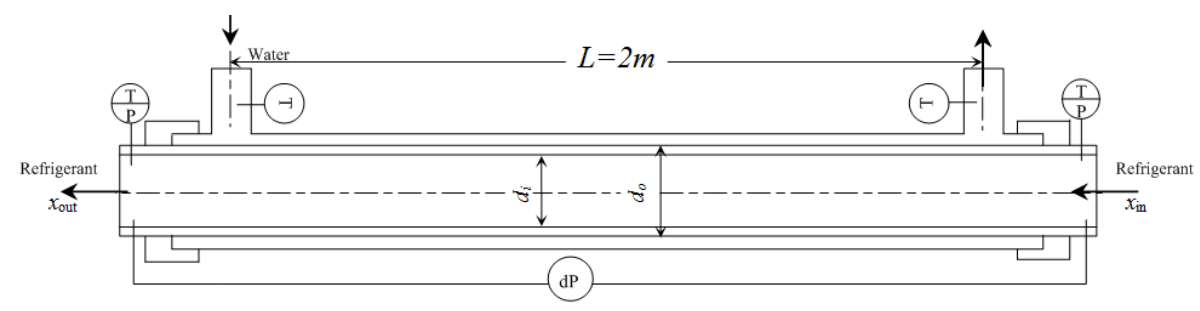

(b)

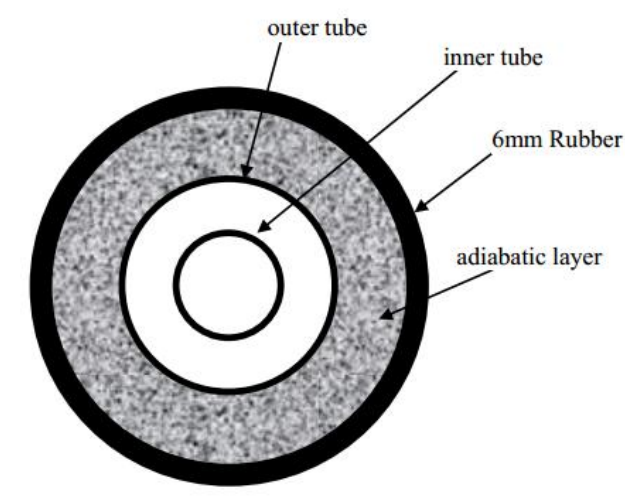

(c)

Fig.3 Schematic of (a) the experimental apparatus, (b) test section; and (c) cross sectional view of test section 


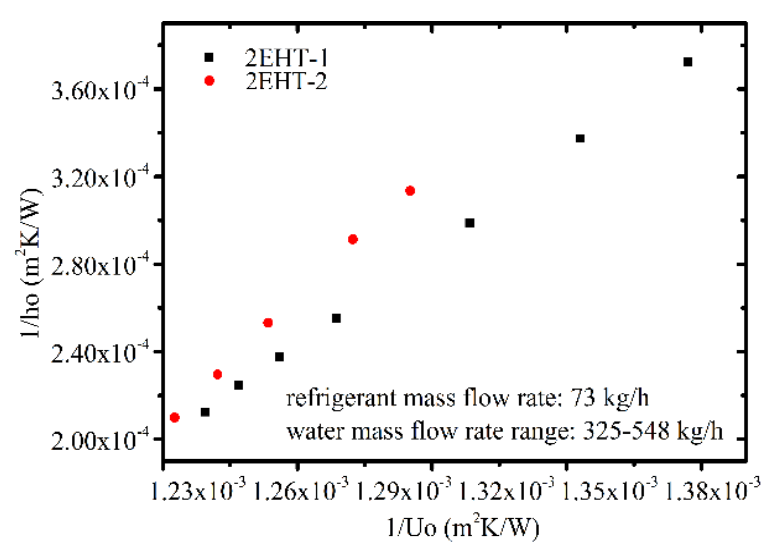

Fig.4 Wilson plot results detailing the annular side enhancement of the 2EHT-1 and 2EHT-2 tubes

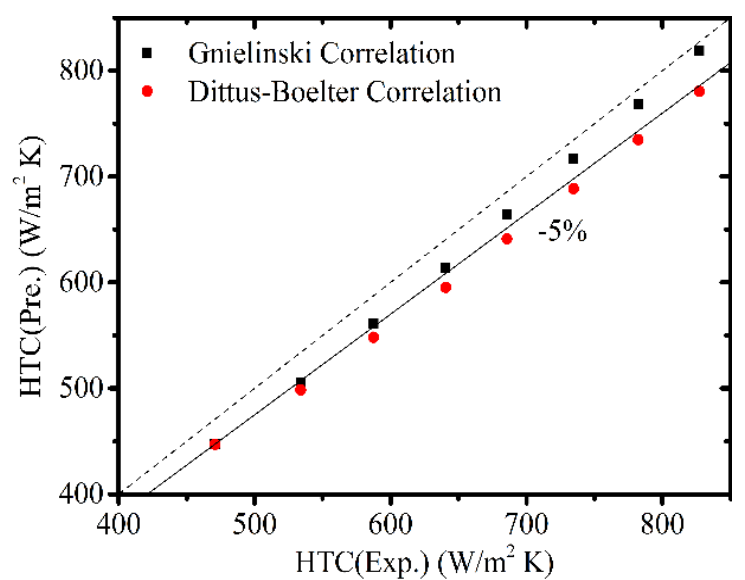

Fig. 6 Comparison of experimental and predicted single-phase heat transfer coefficient in a smooth tube

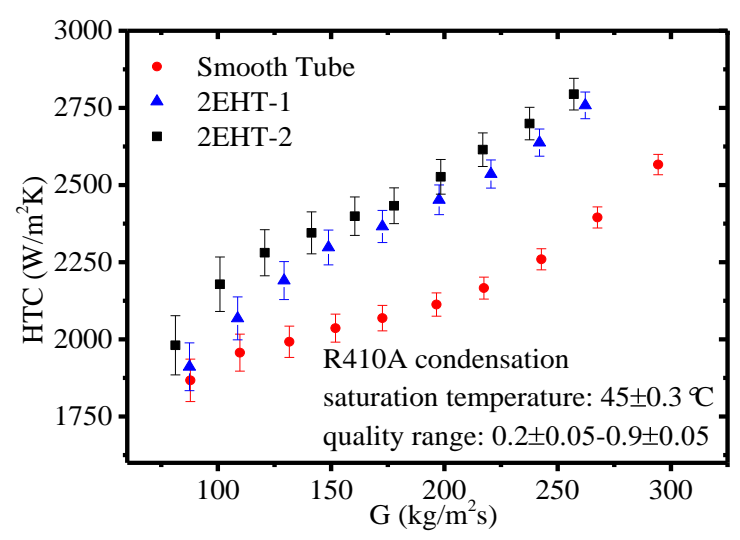

Fig. 8 Comparison of tube side condensation heat transfer coefficient (HTC) as a function of mass flux $(\mathrm{G})$ for enhanced tubes (2EHT-1 and 2EHT-2) and smooth tubes using R410A

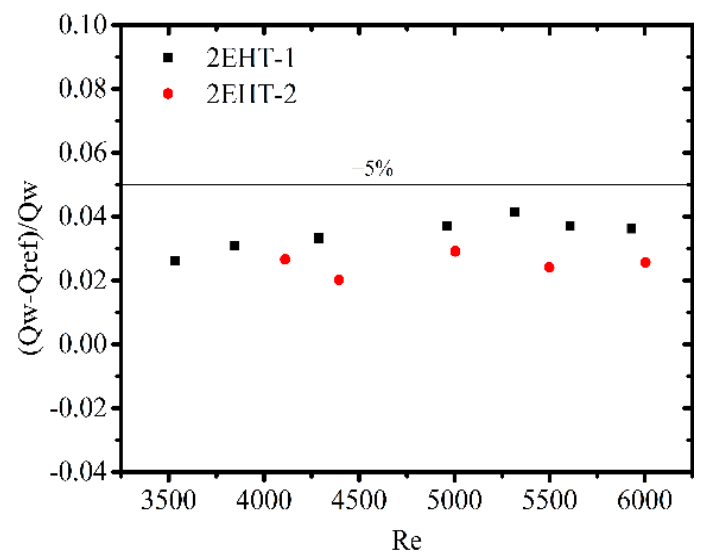

Fig. 5 Single-phase heat balance vs. Reynolds number

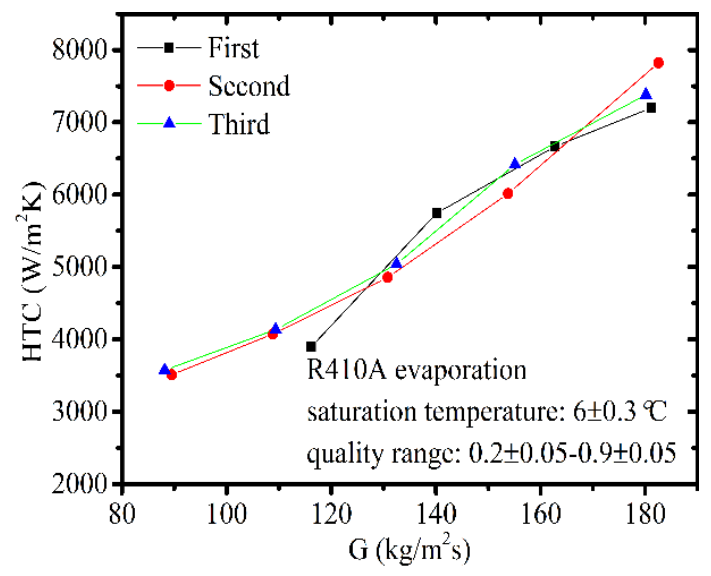

Fig. 7 Tube side evaporation heat transfer coefficient (HTC) as a function of mass flux (G) for the 2EHT-1 tube

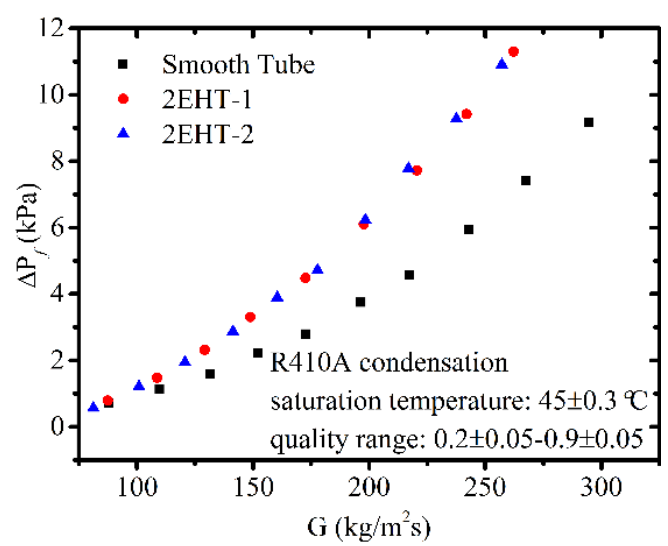

Fig. 9 Comparison of tube side condensation pressure drop as a function of mass flux $(\mathrm{G})$ for enhanced tubes (2EHT-1 and 2EHT-2) and smooth tubes using R410A 


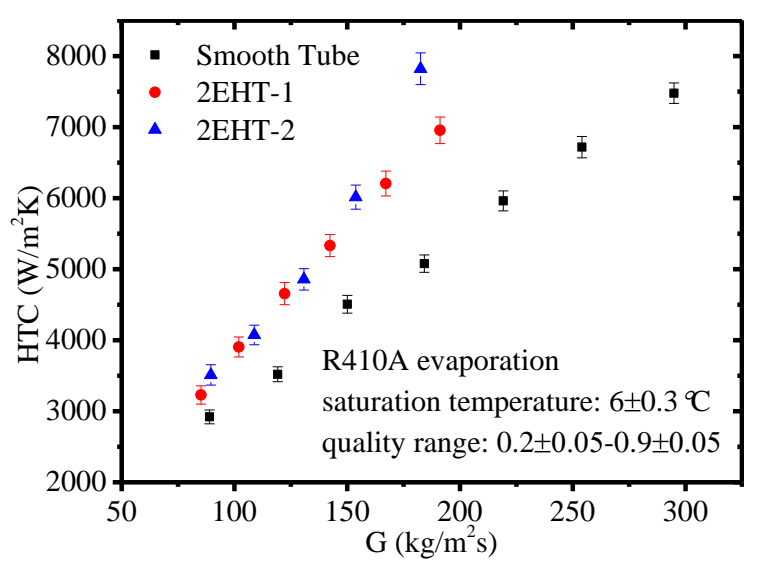

Fig. 10 Comparison of tube side evaporation heat transfer coefficient (HTC) as a function of mass flux (G) for enhanced tubes (2EHT-1 and 2EHT-2) and smooth tubes using R410A

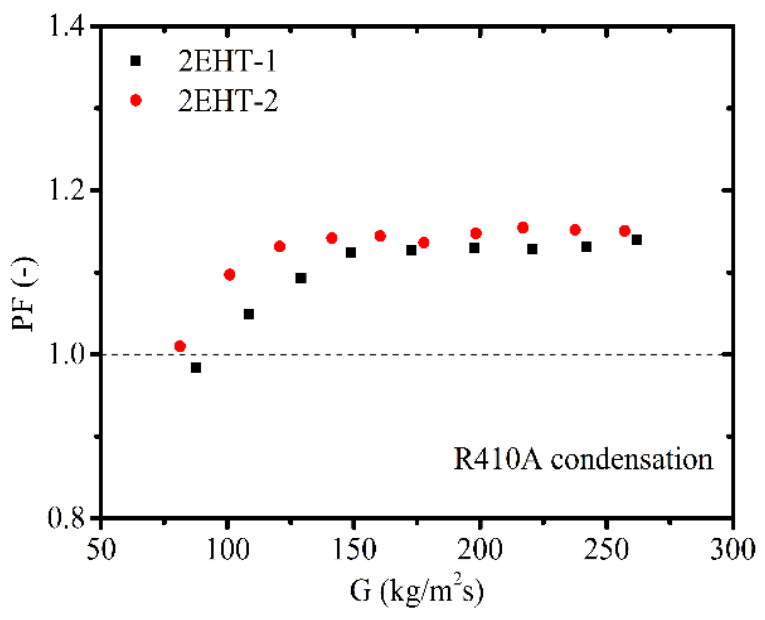

(a)

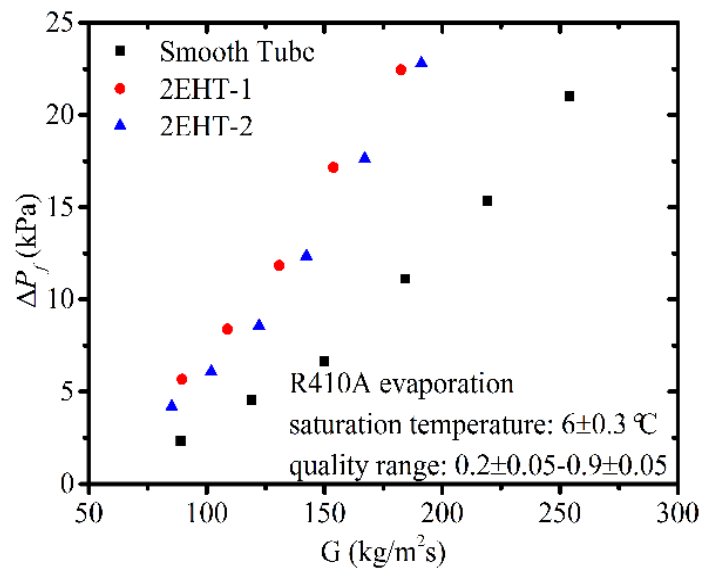

Fig. 11 Comparison of tube side evaporation pressure drop as a function of mass flux $(\mathrm{G})$ for enhanced tubes (2EHT-1 and 2EHT-2) and smooth tubes using R410A.

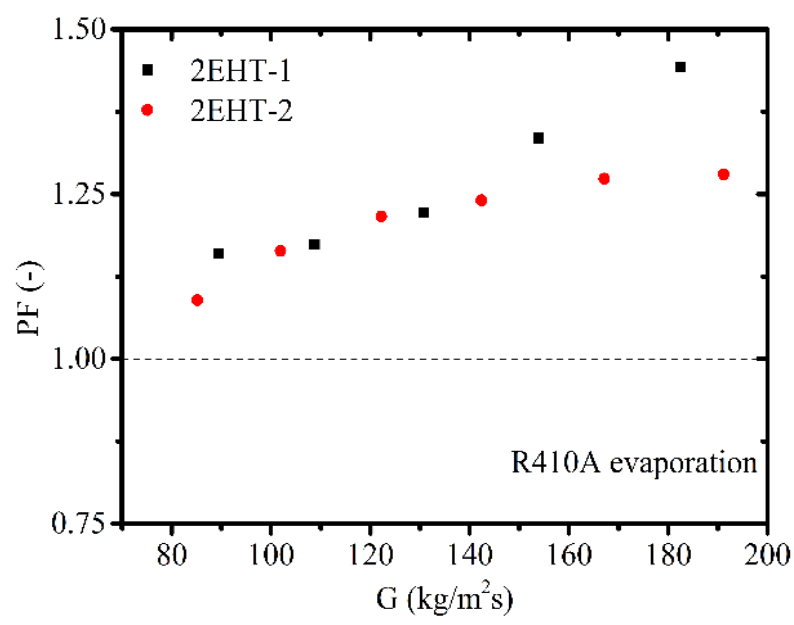

(b)

Fig. 12 Comparison of performance evaluation factor (PF) as a function of mass flux (G) for enhanced tubes (2EHT-1 and 2EHT-2) and smooth tubes using R410A. (a) condensation and (b) evaporation 
Table 1 Relative accuracy for primary measurements and dependent values

\begin{tabular}{ll}
\hline \hline Primary measurements & \\
Diameter & $\pm 0.05 \mathrm{~mm}$ \\
Electricity & $\pm 0.1 \mathrm{~A}$ \\
Voltage & $\pm 0.1 \mathrm{~V}$ \\
Length & $\pm 0.5 \mathrm{~mm}$ \\
Temperature & $\pm 0.1 \mathrm{~K}$ \\
Pressure, range: $0-5000 \mathrm{kPa}$ & $\pm 0.075 \%$ of full scale \\
Differential pressure, range: $0-50 \mathrm{kPa}$ & $\pm 0.075 \%$ of full scale \\
Water flow rate, range: $0-1000 \mathrm{~kg} / \mathrm{h}$ & $\pm 0.2 \%$ of reading \\
Refrigerant flow rate, range: $0-130 \mathrm{~kg} / \mathrm{h}$ & $\pm 0.2 \%$ of reading \\
& \\
Dependent quantities & $\pm 0.892 \%$ \\
Mass flux G, kg/(m $\left.{ }^{2} \mathrm{~s}\right)$ & $\pm 9.54 \%$ for condensation \\
Heat flow rate of water side, $\mathrm{kW}$ & $\pm 6.22 \%$ for evaporation \\
& $\pm 10.64 \%$ for condensation \\
Vapor quality, $x$ & $\pm 8.74 \%$ for evaporation \\
Heat transfer coefficient $\mathrm{h}, \mathrm{W} /\left(\mathrm{m}^{2} \mathrm{~K}\right)$ & $\pm 13.27 \%$ for condensation \\
\hline \hline
\end{tabular}




\section{Nomenclature}

\begin{tabular}{|c|c|c|c|}
\hline$A_{i}$ & inner surface area of test tube, $\mathrm{m}^{2}$ & $\lambda$ & loss efficient of electricity power \\
\hline$A_{o}$ & outer surface area of test tube, $\mathrm{m}^{2}$ & $\mu$ & dynamic viscosity, Pas \\
\hline$c_{p}$ & specific heat, $\mathrm{J} \mathrm{kg}^{-1} \mathrm{~K}^{-1}$ & $\sigma$ & surface tension, $\mathrm{N} \mathrm{m}^{-1}$ \\
\hline$d_{i}$ & inner diameter of test tube, $\mathrm{m}$ & $\rho$ & density, $\mathrm{kg} \mathrm{m}^{-3}$ \\
\hline$d_{o}$ & outer diameter of test tube, $\mathrm{m}$ & $\Delta P_{m}$ & Pressure drop due to density change, $\mathrm{kPa}$ \\
\hline$d_{h}$ & hydraulic diameter, $\mathrm{d}_{\mathrm{h}}=\mathrm{D}_{\mathrm{i}}-\mathrm{d}_{\mathrm{o}}, \mathrm{m}$ & $\varepsilon$ & void fraction \\
\hline$D_{i}$ & inner diameter of outer tube, $\mathrm{m}$ & & \\
\hline$f$ & Fanning friction factor & Subscripts & \\
\hline$F r$ & Froude number & $\exp$ & experimental \\
\hline$g$ & gravitational acceleration, $\mathrm{m} \mathrm{s}^{-2}$ & pre & preheating section \\
\hline$G$ & mass flux, $\mathrm{kg} \mathrm{m}^{-2} \mathrm{~s}^{-1}$ & sens & sensible heat \\
\hline$h$ & heat transfer coefficient, $\mathrm{W} \mathrm{m}^{-2} \mathrm{~K}^{-1}$ & lat & latent heat \\
\hline$h_{l v}$ & latent heat of vaporization, $\mathrm{J} \mathrm{kg}^{-1}$ & wall & wall parameters \\
\hline$k$ & thermal conductivity, $\mathrm{W} \mathrm{m}^{-1} \mathrm{~K}^{-1}$ & ref & refrigerant \\
\hline$L$ & tube length, $\mathrm{m}$ & sat & saturated \\
\hline LMTD & logarithmic mean temperature, $\mathrm{K}$ & in & inlet \\
\hline$P$ & pressure, $\mathrm{kPa}$ & out & outlet \\
\hline$P F$ & performance evaluation factor & $w$ & water \\
\hline $\operatorname{Pr}$ & Prandtl number & $l$ & liquid phase \\
\hline$Q$ & heat transfer rate, $\mathrm{W}$ & $v$ & vapor phase \\
\hline $\operatorname{Re}$ & Reynolds number & $i$ & inner tube surface based parameters \\
\hline$T$ & temperature, $\mathrm{K}$ & $o$ & outer tube surface based parameters \\
\hline$V$ & voltage, $\mathrm{V}$ & $l v$ & liquid phase to vapor phase \\
\hline$I$ & electric current, A & EHT & enhanced tube \\
\hline$W$ & mass flow rate, $\mathrm{kg} \mathrm{s}^{-1}$ & $m$ & momentum \\
\hline We & Weber number & $S L$ & sudden enlarge \\
\hline$x$ & vapor quality & $S C$ & sudden contraction \\
\hline$X_{t t}$ & Martinelli parameter & $O N B$ & onset of nucleate boiling \\
\hline \multicolumn{2}{|c|}{ Greek symbols } & $s$ & smooth tube \\
\hline
\end{tabular}

$\triangle P \quad$ pressure drop, $\mathrm{kPa}$ 